Michael Seear FRCPC, Ignacio Malagon FRCA, Henry Hui MRCP, John Alexander MRCP, Christopher Daoust RRT, Peter Skippen FANZCA

\section{Evaluation of a mathe- matical model to predict intrapulmonary shunt non-invasively}

Purpose: We have previously published a mathematical-model of oxygen transport. Using several physiological assumptions, the model provides a non-invasive estimate of intrapulmonary shunt. During a larger study of lung injury in a pig model, we had the opportunity to check the validity of our assumptions and the accuracy of the model's predictions.

Methods: We used six female pigs, average weight $12.8 \mathrm{~kg}$. Following general anesthesia, tracheostomy and insertion of pulmonary venous and arterial lines, lung injury was induced by repeated saline lung lavage. Using hemodynamic measurements made at different levels of inspired oxygen, intrapulmonary shunt was calculated both by the traditional shunt equation and also by our mathematical model based on non-invasive measurements of $\mathrm{F}_{1} \mathrm{O}_{2}$ and $\mathrm{SaO}_{2}$.

Results: There was good agreement between the two methods of shunt calculation. Using linear regression the correlation coefficient was 0.95 . Bland and Altman analysis showed a bias of -0.8 and precision of $12 \%$.

Conclusion: In a controlled setting, intrapulmonary shunt can be estimated from non-invasive measurements to a reasonable degree of accuracy. However, the calculation requires too many assumptions to be of general clinical value. The equations used provide a validated physiological model that acts as a useful tool for teaching cardiorespiratory physiology.

Objectif : Nous avons publié déjà un modèle mathématique de transport d'oxygène qui, en utilisant certaines hypothèses physiologiques, fournit une estimation non effractive du shunt intrapulmonaire. Lors d'une étude plus importante de la lésion pulmonaire avec un modèle porc, nous avons pu vérifier la validité de nos hypothèses et l'exactitude des prédictions modélisées.

Méthode : Nous avons utilisé six porcs femelles dont le poids moyen était de 12,8 kg. Après l'anesthésie générale, la trachéotomie et l'insertion de cathéters artériel et veineux pulmonaires, la lésion du poumon a été provoquée par un lavage du poumon avec une solution salée. Le shunt intrapulmonaire a été calculé, à partir de mesures hémodynamiques réalisées à différents niveaux d'oxygène inspiré, selon l'équation de shunt habituelle et aussi selon notre modèle mathématique basé sur les mesures non effractives de $\mathrm{F}_{1} \mathrm{O}_{2}$ and $\mathrm{SaO}_{2}$.

Résultats : Il y avait une bonne correspondance entre les résultats des deux méthodes de calcul de shunt. Selon la courbe de régression linéaire, le coefficient de corrélation était de 0,95. L'analyse de Bland et Altman a montré un biais de $-0,8$ et une précision de $12 \%$.

Conclusion: Dans une situation contrôlée, le shunt intrapulmonaire peut être évalué avec une précision acceptable à partir de mesures non effractives. Cependant, le calcul nécessite beaucoup trop de suppositions pour avoir une valeur clinique générale. Les équations utilisées fournissent un modèle physiologique validé qui peut servir d'outil d'enseignement de la physiologie cardiorespiratoire.

From the Department of Pediatrics, University of British Columbia, Vancouver, Canada.

Address correspondence to: Dr. Michael Seear, British Columbia's Children's Hospital, Pediatric Intensive Care Unit, 4480 Oak Street, Vancouver, B.C., V6H 3V4. Phone: 604-875-2119; Fax: 604-875-3293; E-mail: mseear@wpog.childhosp.bc.ca Accepted for publication February 7,1999 
A CCURATE assessment of the efficiency of oxygen transfer from inspired gas to arterial blood is an important part of the management of any critically ill child. The simplest estimates of oxygen transfer are based on the difference in partial pressures between alveolar oxygen $\left(\mathrm{P}_{\mathrm{A}} \mathrm{O}_{2}\right)$ calculated by the alveolar gas equation ${ }^{1}$ and measured arterial oxygen $\left(\mathrm{PaO}_{2}\right)$. Whether the relationship between these variables is expressed as a gradient $\left(\mathrm{P}_{\mathrm{A}} \mathrm{O}_{2}-\mathrm{PaO}_{2}\right)$, a ratio $\left(\mathrm{PaO}_{2} / \mathrm{P}_{\mathrm{A}} \mathrm{O}_{2}\right)$ or an index $\left(\left(\mathrm{P}_{\mathrm{A}} \mathrm{O}_{2}-\mathrm{PaO}_{2}\right) / \mathrm{PaO}_{2}\right)$, the results have been shown to be unreliable indicators of the actual percentage of pulmonary venous flow that is shunted through unventilated alveoli. ${ }^{2}$ This quantity is best estimated by the shunt equation: ${ }^{3}$

Equation 1

$$
\frac{\mathrm{Q}_{\mathrm{s}}}{\mathrm{Q}_{\mathrm{t}}}=\frac{\left(\mathrm{C}_{\mathrm{c}} \mathrm{O}_{2}-\mathrm{C}_{\mathrm{a}} \mathrm{O}_{2}\right)}{\left(\mathrm{C}_{\mathrm{c}} \mathrm{O}_{2}-\mathrm{C}_{\mathrm{v}}-\mathrm{O}_{2}\right)}
$$

where $Q_{s}$ is shunt flow, $Q_{t}$ is cardiac output and $C_{c}, O_{2}$, $\mathrm{C}_{\mathrm{a}} \mathrm{O}_{2}$ and $\mathrm{C}_{\mathrm{v}} \mathrm{O}_{2}$ are end capillary, arterial and mixed venous oxygen contents. Unfortunately, the terminology of pulmonary shunt varies. At $100 \%$ inspired oxygen, this equation predicts the true shunt. At lower levels of $\mathrm{F}_{\mathrm{I}} \mathrm{O}_{2}$, the calculated value includes a component due to ventilation/perfusion mismatch and is often referred to as venous admixture $\left(Q_{a v}\right)$. Throughout this paper, the term $Q_{s}$ refers to the calculated shunt at any level of $\mathrm{F}_{\mathrm{I}} \mathrm{O}_{2}$.

Clinical application of the shunt equation is limited by the requirement for a mixed venous blood sample. Two methods have been used to estimate $\mathrm{C}_{\mathrm{v}} \mathrm{O}_{2}$ without the need for a pulmonary artery catheter. A vena caval blood sample can be substituted with fair accuracy $^{4}$ but it still requires the use of a central line. Alternatively, an estimated shunt can be calculated using an assumed arterial-venous oxygen content difference ${ }^{5}\left(\mathrm{C}_{(\mathrm{a}-\mathrm{v})} \mathrm{O}_{2}\right)$. Although $\mathrm{C}_{(\mathrm{a}-\mathrm{v})} \mathrm{O}_{2}$ can vary widely ${ }^{6}$ with critical illness, this technique has been updated ${ }^{7}$ and used clinically. ${ }^{8}$

We previously published a mathematical model of oxygen transport that did not require a term for $\mathrm{C}_{\mathrm{v}} \mathrm{O}_{2}{ }^{9}$ so allowing us to calculate $Q_{s}$ non-invasively. The model is easily displayed on a standard computer spreadsheet and has proved to be a useful teaching tool but, until recently, we had no opportunity to test its physiological validity.

The main aim of this study was to examine the accuracy of our predictions by comparing predicted values of $Q_{s}$ with calculated values measured during a larger study of acute lung injury in pigs. We also wished to test the validity of the assumptions that have to be made in order to use the model.

\section{Methods \\ Mathematical model}

We have previously described a mathematical model of oxygen transport. ${ }^{9}$ Its derivation depends on the resolution of the shunt equation and the Fick equation. The shunt equation (eq 1) describes the relationship between pulmonary shunt fraction $\left(Q_{s} / Q_{t}\right)$ and the blood oxygen contents at various points in the pulmonary circuit $\left(\mathrm{C}_{\mathrm{a}} \mathrm{O}_{2}, \mathrm{C}_{\mathrm{v}} \mathrm{O}_{2}\right.$ and $\left.\mathrm{C}_{\mathrm{c}} \mathrm{O}_{2}\right)$. The Fick equation ${ }^{10}$ describes the relationship between oxygen consumption $\left(\mathrm{V}_{\mathrm{O} 2}\right)$, cardiac output $\left(\mathrm{Q}_{\mathrm{t}}\right)$ and the arterial-venous oxygen content difference.

Equation 2

$$
\mathrm{Q}_{\mathrm{t}}=\frac{\mathrm{V}_{\mathrm{o} 2}}{\mathrm{C}_{\mathrm{a}} \mathrm{O}_{2} \cdot \mathrm{C}_{\mathrm{v}} \mathrm{O}_{2}}
$$

At equilibrium, equations 1 and 2 can be considered as simultaneous. They can be rearranged to solve for $\mathrm{Q}_{\mathrm{s}}$ after substituting for $\mathrm{C}_{\mathrm{v}} \mathrm{O}_{2}$.

Equation 3

$$
Q_{s}=\frac{Q_{t}\left(C_{c} O_{2}-C_{a} O_{2}\right)}{C_{c} O_{2}-C_{a} O_{2}+\frac{V_{o 2}}{Q_{t}}}
$$

The result is a predictive model for $Q_{s}$ that does not require the calculation of $\mathrm{C}_{\mathrm{v}} \mathrm{O}_{2}$. However, the list of unknown variables is long. Apart from $\mathrm{Q}_{\mathrm{t}}$ and $\mathrm{V}_{\mathrm{O} 2}$, the calculation of $\mathrm{C}_{\mathrm{c}^{\prime}} \mathrm{O}_{2}$ and $\mathrm{C}_{\mathrm{a}} \mathrm{O}_{2}$ requires the following: barometric pressure $\left(\mathrm{P}_{\mathrm{B}}\right)$, saturated water vapour pressure $\left(\mathrm{P}_{\text {swv }}\right), \mathrm{SaO}_{2}, \mathrm{~F}_{\mathrm{I}} \mathrm{O}_{2}, \mathrm{PaO}_{2}$, hemoglobin $(\mathrm{Hb})$, respiratory quotient $(\mathrm{RQ})$ and $\mathrm{PaCO}_{2}$. Several of these variables can be measured with minimal invasion $\left(\mathrm{F}_{\mathrm{I}} \mathrm{O}_{2}, \mathrm{SaO}_{2}, \mathrm{PaCO}_{2}, \mathrm{P}_{\mathrm{B}}, \mathrm{Hb}\right) . \mathrm{PaO}_{2}$ can be derived from $\mathrm{SaO}_{2}$ using Thomas' algorithm. ${ }^{11}$ Based on another study of cardiorespiratory variables in critically ill children, ${ }^{12}$ we found that the remaining unknown variables remain surprisingly constant in paralysed children $\left(\mathrm{V}_{\mathrm{O} 2}=4.5 \mathrm{ml} \cdot \mathrm{kg}^{-1} \cdot \mathrm{min}^{-1}, \mathrm{~V}_{\mathrm{CO} 2}=3.5\right.$ $\mathrm{ml} \cdot \mathrm{min}^{-1} \cdot \mathrm{kg}^{-1}, \mathrm{Q}_{\mathrm{t}}=80 \mathrm{ml} \cdot \mathrm{min}^{-1} \cdot \mathrm{kg}^{-1}, \mathrm{Hb}=120$ g. $\left.L^{-1}\right)$. Substituting these values into equation 3 , it is possible to construct an iso-shunt diagram (Figure 1). Using this graph, $Q_{s}$ can be predicted based on noninvasive measurements of $\mathrm{S}_{2} \mathrm{O}_{2}$ and $\mathrm{F}_{\mathrm{I}} \mathrm{O}_{2}$. The reliability of the prediction clearly depends on the validity of the underlying assumptions. 


\section{Animal preparation}

Our investigation was part of a larger study designed to investigate the management of acute lung injury. The study was approved by the Hospital Ethics Committee and the University of British Columbia Animal Care Committee. Six pigs with an average weight $12.8 \mathrm{~kg}$ were studied. Following premedication $\left(0.02 \mathrm{mg} \cdot \mathrm{kg}^{-1}\right.$ atropine, $20 \mathrm{mg} \cdot \mathrm{kg}^{-1}$ ketamine, $0.2 \mathrm{mg} \cdot \mathrm{kg}^{-1}$ midazolam $\mathrm{im}$ ), anesthesia was induced with inhaled halothane and oxygen and then maintained with a thiopental infusion $\left(3.3 \mathrm{mg} \cdot \mathrm{kg}^{-1} \cdot \mathrm{hr}^{-1}\right)$ and pancuronium boluses $\left(0.1 \mathrm{mg} \cdot \mathrm{kg}^{-1}\right)$ to maintain muscle relaxation. The lungs were intubated and ventilated at a rate of $25 \mathrm{bpm}$, tidal volume $10 \mathrm{ml} \cdot \mathrm{kg}^{-1}$ and end expiratory pressure of $5 \mathrm{~cm} \mathrm{H}_{2} \mathrm{O}$.

\section{Study design}

Following preparation of the animal, acute lung injury was induced by recurrent lung lavage with warm saline until $\mathrm{P}_{\mathrm{a}} \mathrm{O}_{2}$ was less than $100 \mathrm{~mm} \mathrm{Hg}$ at $\mathrm{F}_{\mathrm{I}} \mathrm{O}_{2}$ of 1.0 . The inspired oxygen was reduced from 1.0 to 0.21 in five steps followed by an equilibration period of $\mathbf{3 0}$ min. At each level, simultaneous samples of systemic and pulmonary arterial bloods were taken and analysed immediately to obtain the following data: $\mathrm{Hb}, \mathrm{SaO}_{2}, \mathrm{PaO}_{2}, \mathrm{PaCO}_{2}, \mathrm{~S}_{\mathrm{V}} \mathrm{O}_{2}, \mathrm{P}_{\mathrm{V}} \mathrm{O}_{2}$. Heart rate and cardiac output were also measured. Subsequently, two independent observers calculated $Q_{s}$ : one using the classical shunt equation (eq 1 ) and the other using only non-invasive measurements of $\mathrm{F}_{\mathrm{I}} \mathrm{O}_{2}$ and $\mathrm{SaO}_{2}$ to estimate $Q_{s}$ using the iso-shunt diagram (Figure l).

\section{Statistical analysis}

The estimates of $Q_{s}$ were compared using two techniques. The first was linear regression using the method of least squares analysis. The degree of agreement was expressed as a correlation coefficient. Comparisons were also made using the Bland and Altman statistical method. ${ }^{13}$ Briefly, this method involves first a graphic representation of the plot of the difference between the paired results against their mean value. The agreement between the two measurements can then be summarised by calculating the bias (mean of the paired differences) and the precision, or limits of agreement, represented by the standard deviation of the mean difference. If the differences are normally distributed, one can expect $95 \%$ of the values to lie between these limits.

\section{Results}

We found it more difficult to induce lung injury in the pigs than previous reports had suggested. ${ }^{14}$ In addition, once injury was established, it did not remain

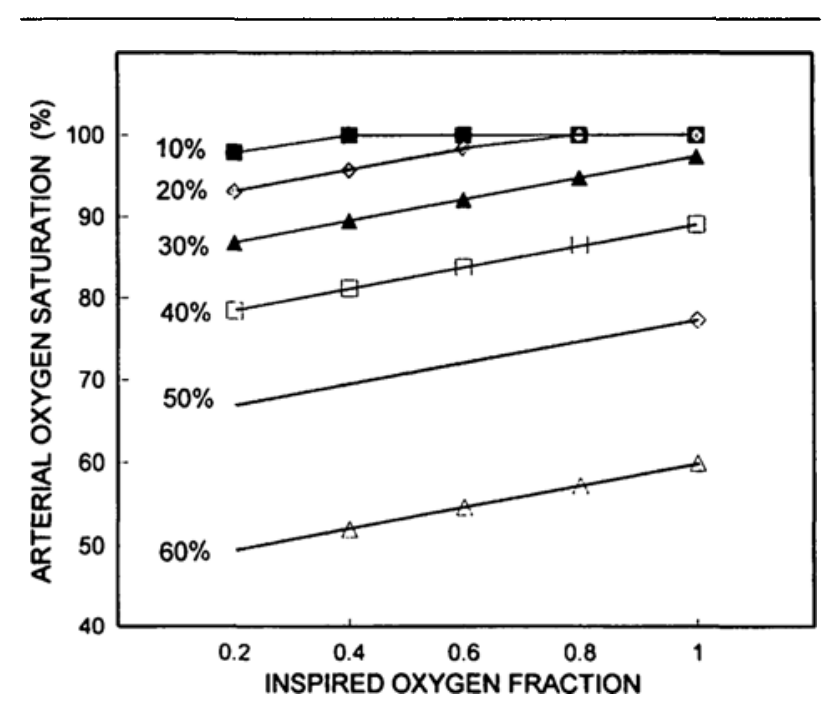

FIGURE 1 The effect of varying inspired $\mathrm{O}_{2}$ fraction $\left(\mathrm{F}_{\mathrm{r}} \mathrm{O}_{2}\right)$ upon arterial $\mathrm{O}_{2}$ saturation $\left(\mathrm{SaO}_{2}\right)$ predicted for levels of pulmonary shunt fraction $\left(Q_{s} / Q_{1}\right)$ from $10 \%$ to $60 \%$. Calcularions are based on a hypothetical child, $\mathrm{Q}_{\mathrm{t}}=80 \mathrm{ml} \cdot \mathrm{min}^{-1} \cdot \mathrm{kg}^{-1}, \mathrm{~V}_{\mathrm{O} 2}=4.5$ $\mathrm{ml} \cdot \mathrm{min}^{-1} \cdot \mathrm{kg}^{-1}, \mathrm{~V}_{\mathrm{CO} 2}=3.5 \mathrm{ml} \cdot \mathrm{min}^{-1} \cdot \mathrm{kg}^{-1}, \mathrm{Hb}=120 \mathrm{~g} \cdot \mathrm{L}^{-1}$.

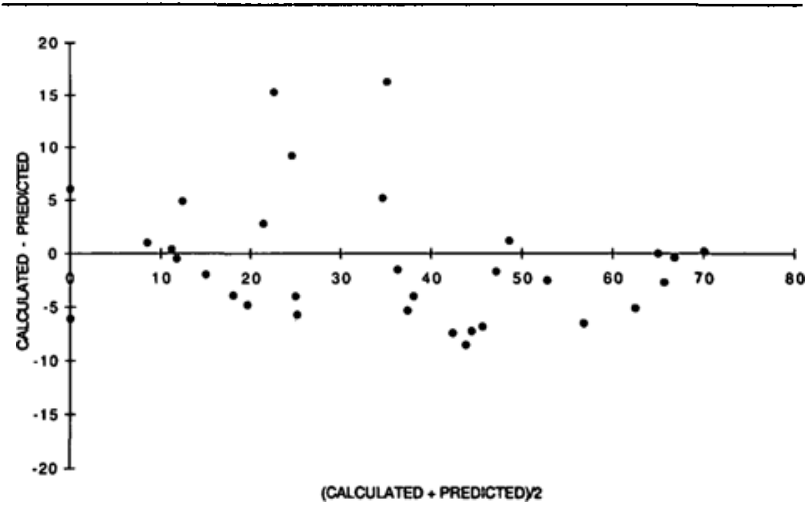

FIGURE 2 Measured shunt fraction $\left(Q_{\mathrm{s}} / \mathrm{Q}_{\mathrm{t}}\right)$ compared with predicted values using the technique of Bland and Altman. The difference is plotted against their mean value. Bias $=0.8 \%$, precision $=12.2 \%$.

stable over the four hours of the experiment; four animals worsened while two improved.

Thirty-two paired measurements of $Q_{s}$ were made in six animals. The correlation coefficient $(r)$, calculated by the method of least squares was 0.95 . The predicted values of $Q_{s}$ based on our assumed values of $Q_{t}$, $\mathrm{V}_{\mathrm{O} 2}, \mathrm{~V}_{\mathrm{CO} 2}$ and $\mathrm{Hb}$ were generally lower than the calculated measurements. This becomes clear when comparison is made using the method of Bland and 
Altman ${ }^{13}$ (Figure 2). It can be seen that the majority of points fall below the line. A few positive outliers above the line balance this trend so the calculated bias is only $0.8 \%$. The precision was $12.2 \%$.

The initial assumptions of $\mathrm{Q}_{\mathrm{t}}, \mathrm{V}_{\mathrm{O} 2}, \mathrm{~V}_{\mathrm{CO} 2}$ and $\mathrm{Hb}$ required for the prediction of iso-shunt curves for children (Figure 1) appeared to be reasonable. Mean values measured in pigs were all slightly higher $\left(Q_{r}=92\right.$ vs 80 $\mathrm{ml} \cdot \mathrm{min}^{-1} \cdot \mathrm{kg}^{-1}, \mathrm{~V}_{\mathrm{O} 2}=5.1$ ps $4.5 \mathrm{ml} \cdot \mathrm{min}^{-1} \cdot \mathrm{kg}^{-1}, \mathrm{~V}_{\mathrm{CO} 2}=$ 3.9 ps $3.5 \mathrm{ml} \cdot \mathrm{min}^{-1} \cdot \mathrm{kg}^{-1}, \mathrm{Hb}=125$ vs $120 \mathrm{~g} \cdot \mathrm{L}^{-1}$ ). The effect of an increased $V_{O 2}$ was balanced by a higher $Q_{t}$ so that the predicted values of $Q_{s}$ did not change.

\section{Discussion}

We calculated intrapulmonary shunt using a non-invasive technique and compared it to an invasive "gold standard" in an animal model of acute lung injury. Although the correlation coefficient between the two measurements was 0.95 , the scatter of results demonstrated by the Bland and Altman plot (Figure 2) shows that the non-invasive prediction can only be viewed as an approximation to the true value. Our results are comparable with other non-invasive techniques for estimating $Q_{s} / Q_{r}$. Calculations based on substituting a vena caval blood sample generated a correlation coefficient of $0.97^{4}$ which compares well with our coefficient of 0.95 . Similarly, Hope's ${ }^{15}$ updated validation of Benatar's "virtual shunt" based on an assumed $\mathrm{C}_{(\mathrm{a}-\mathrm{v})} \mathrm{O}_{2}{ }^{5}$ produced a bias of $0.7 \%$ and a precision of $15.8 \%$ which, again, compares well with our measurements of $0.8 \%$ and $12.2 \%$ respectively.

There is a limit to the approximations that any mathematical equation will tolerate. The various attempts to estimate $Q_{S} / Q_{r}$ without the need for a pulmonary arterial blood sample are no exception. Small improvements in accuracy are possible by substituting measured values for some of the assumed variables ${ }^{15}$ but the final result is still only a prediction. The assumptions underlying our mathematical model are based on extensive experience with critically ill children ${ }^{12}$ but clearly cannot be expected to sum up every single patient. Once a reliable idea of the hemodynamic variables of a particular population is obtained, it would be possible to "tune" the iso-shunt lines for that group. For instance, it would be possible to remove the small bias noted in the Bland and Altman plot by changing some of the assumed variables. However, the small improvement in accuracy would hardly justify the extra work.

The recent debate concerning the value of pulmonary artery catheters ${ }^{16}$ reflects the trend (particularly in pediatrics) towards non-invasive monitoring. A balance has to be found between the information derived from invasive catheters and the potential risk of side effects. At a time when non-invasive techniques are increasing in sophistication, it is probable that the necessity to derive $Q$ - by whatever means - will decrease, making it unlikely that iso-shunt lines will have much clinical value. However, a detailed understanding of cardiopulmonary physiology will always be essential. This study has shown that our predictive equation provides a realistic model that gives a useful tool for teaching the physiology of oxygen transport.

\section{References}

1 Nunn J. Applied Respiratory Physiology, 4th ed. Oxford: Butterworth Press, 1993: 195-6.

2 Cane $R D$, Shapiro BA, Templin $R$, Walther $K$. Unreliability of oxygen tension-based indices in reflecting intrapulmonary shunting in critically ill parients. Crit Care Med 1998; 16: 1243-5.

3 Nunn J. Applied Respiratory Physiology, 4th ed. Oxford: Butterworth Press, 1993: 178-9.

4 Reinhart $K$, Rudolph $T$, Bredle DL, Hannemann $L$, Cain SM. Comparison of central-venous to mixedvenous oxygen saturation during changes in oxygen supply/demand. Chest 1989; 95: 1216-21.

5 Benatar S, Hewlett A, Nunn J. The use of iso-shunt lines for control of oxygen therapy. Br J Anaesth 1973; 45: 711-8.

6 Harrison RA, Davison $R$, Shapiro BA. Reassessment of the assumed $A-V$ oxygen content difference in the shunt equation. Anesth Analg 1975; 54: 198-202.

7 Roe PG, Jones JG. Analysis of factors which affect the relationship between inspired oxygen partial pressure and arterial oxygen saturation. $\mathrm{Br} J$ Anaesth 1993; 71: 488-94.

8 Dingley J, Hope DA, Vaughan RS. The use of a noninvasive method to measure intrapulmonary shunt during one-lung anaesthesia. Anaesthesia 1996; 51: 654-7.

9 Seear M, Anderson B, Hall R, Hui H. Mathematical model of oxygen transport: a teaching aid for normal physiology adaptable to extracorporeal oxygenation circuits. Am J Physiol (Adv Physiol Educ 13) 1995; 268: S32-9.

10 Nunn J. Applied Respiratory Physiology, 4th ed. Oxford: Butterworth Press, 1993: 152.

11 Thomas $L J J r$. Algorithms for selected blood acid-base and blood gas calculations. J Appl Physiol 1972; 33: 154-8.

12 Seear M, Wensley D, MacNab A. Oxygen consumptionoxygen delivery relationship in children. J Pediatr 1993; 123: 208-14.

13 Bland JM, Altman DG. Statistical methods for assessing agreement between two methods of clinical measurement. Lancet 1986; 1: 307-10. 
14 Nielsen JB, Sjöstrand UH, Edgren EL, LichtwarckAschoff $M$, Svensson BA. An experimental study of different ventilatory modes in piglets in severe respiratory distress induced by surfactant depletion. Intensive Care Med 1991; 17: 225-33.

15 Hope DA, Jenkins BJ, Willis $N$, Maddock $H$, Mapleson $W W$. Non-invasive estimation of venous admixture; validation of a new formula. $\mathrm{Br}$ J Anaesth 1995; 74: $538-43$.

16 Connors AF Jr, Speroff T, Dawson NV, et al. The effectiveness of right heart catheterization in the initial care of critically ill patients. JAMA 1996; 276: 889-97. 